\title{
EFEKTIVITAS MODEL PEMBELAJARAN THINK-TALK-WRITE DALAM MENINGKATKAN KOMUNIKASI MATEMATIS MAHASISWA PENDIDIKAN MATEMATIKA
}

\author{
Siska Candra Ningsih \\ FKIP Universitas PGRI Yogyakarta \\ E-mail : siskazamri@gmail.com
}

\begin{abstract}
This research has aims to determine the effectiveness of learning model Think-TalkWrite (TTW) and determine whether the learning TTW modelis more effective than conventional learning to improve student mathematical communication. The research is a quasi experimental research. The populationin this research were all students ofthe second semester in Mathematics Education department. They are divided into four parallel classes. Samples were IIA2 class as the control class and the IIA1 class as a class experiment in Number Theory lesson. The instrument in this researcsh was test of mathematical communication. The analysies of data use SPSS 16, the proportion test of one population, and t test. The hypotesis tests use the proportion test of one population and t test. Based on the results of this research were concluded that : (1) The mathematical learning by learning model Think-TalkWrite is effective to improve the mathematical communication students. It can be proved fromthe results of proportion testonan experimental class of mathematical communication valueis $1.87>z$ table with a significance level 5\%. Z table is 1.64. (2)The learning model Think-Talk-Write more effective than conventional approaches. It can be proved from the results of t test. The value of mathematical communicationis $2.07>$ t table with a significance level 5\%. t table is 1.67.
\end{abstract}

Keywords: Learning model Think-Talk-Write, Mathematical communication skill

\section{PENDAHULUAN}

Komunikasi dalam kehidupan ini sangatlah penting. Deni (2011) mengartikan komunikasi sebagai proses penyampaian pesan dari penyampai pesan (komunikator) kepada penerima pesan (komunikan) sehingga tercapai kesamaan pengertian atau pesan yang disampaikan. Dalam matematika, komunikasi tentu sangat dibutuhkan. Sebagaimana dirumuskan National Council of Teacher of Mathematics (2000) tujuan pembelajaran matematika adalah : (1) belajar untuk berkomunikasi (mathematical communication); (2) belajar untuk bernalar (mathematical reasoning); (3) 
belajar untuk memecahkan masalah (mathematical Problem Solving); (4) belajar untuk mengaitkan ide (mathematical Connection) dan (5) pembentukan sikap positif terhadap matematika (positive attitudes toward mathematics).

Namun dalam pembelajaran matematika saat ini, kenyataan yang sering kita hadapi adalah siswa-siswa sekolah menengah tidak mampu berkomunikasi dalam matematika dengan baik dan benar.Mereka merasa takut dan menganggap matematika sebagai mata pelajaran yang sangat sulit dan membosankan.Besar kemungkinan gambaran siswa yang keliru terhadap matematika tersebut disebabkan oleh pengalaman mereka belajar matematika yang hanya dipenuhi dengan rumusrumus dan simbol-simbol yang tidak mereka mengerti dengan pasti. Kekeliruan guru dalam mengkomunikasikan konsep, teoremateorema dan simbol-simbol dalam matematika tentu sangat mempengaruhi pandangan siswa terhadap matematika dan cara siswa dalam komunikasi matematika baik lisan ataupun tulisan.

Mahasiswa Program Studi Pendidikan Matematika UPY adalah mahasiswa yang dipersiapkan untuk menjadi seorang guru matematika untuk tingkat Sekolah Menengah Pertama dan Sekolah Menegah Atas.Sebagai seorang calon guru matematika, disamping memiliki ilmu kependidikan dan ilmu matematika itu sendiri, mereka juga dituntut memiliki kemampuan komunikasi matematis yang baik, baik komunikasi matematis secara lisan ataupun tulisan, agar dapat merubah pandangan siswa-siswa sekolah menengah yang keliru terhadap matematika.

$$
\text { Mengingat pentingnya }
$$

komunikasi matematis bagi guru dan calon guru, tetapi kenyataannya masih banyak mahasiswa calon guru tersebut yang masih lemah dalam komunikasi matematis maka penelitian tentang cara-cara meningkatkan komunikasi matematis ini sangat penting untuk dilakukan. Oleh karena itu peneliti merasa perlu melakukan penelitian tentang komunikasi matematis mahasiswa calon guru matematika di UPY agar dapat lebih ditingkatkan lagi.

Model pembelajaran ThinkTalk-Write merupakan salah satu model pembelajaran yang dapat meningkatkan kemampuan komunikasi matematis mahasiswa. Model pembelajaran yang diperkenalkan oleh Huinker dan Laughlin ini pada dasarnya dibangun melalui proses berfikir, berbicara dan menulis.

Oeh karena itu, tujuan dar penelitian ini adalah untuk mengetahui efektivitas model pembelajaran Think-Talk-Write dalam meningkatkan kemampuan komunikasi matematis mahasiswa Pendidikan Matematika UPY dibandingkan dengan pembelajaran konvensional yang masih sering dipakai oleh dosen di universitas. 


\section{METODE PENELITIAN}

Jenis penelitian ini adalah penelitian eksperimen semu (quasi experimental). Penelitian dilaksanakan di Universitas PGRI Yogyakarta, Program Studi Pendidikan Matematika Semester II pada mata kuliah Teori Bilangan.Desain penelitian yang akan digunakan dalam penelitian ini adalah true experimental design bentuk Posttest Only Control Design. Adapun paradigma desain penelitian yang dipakai dalam penelitian ini dapat digambarkan pada tabel berikut:

Tabel 1. Desain Penelitian

\begin{tabular}{|l|c|c|}
\hline \multicolumn{1}{|c|}{ Kelompok } & Perlakuan & Posttest \\
\hline Eksperimen & $\mathrm{X}$ & $\mathrm{O}_{\mathrm{E}}$ \\
\hline Kontrol & - & $\mathrm{O}_{\mathrm{K}}$ \\
\hline
\end{tabular}

Keterangan:

$\mathrm{O}_{\mathrm{E}} \quad$ : Posttest kelas eksperimen

$\mathrm{O}_{\mathrm{K}}$ : Posttest kelas kontrol

$\mathrm{X}$ : Pembelajaran dengan menggunakan metode ThinkTalk-Write

- : Pembelajaran konvensional. (Sugiyono, 2009).

Populasi dalam penelitan ini adalah semua mahasiswa Program Sudi Pendidikan Matematika semester II yang terbagi dalam 4 kelas paralel yaitu A1, A2, A3 dan A4. Sesuai dengan jenis penelitian yaitu penelitian eksperimen, maka diambil sampel dua kelas dari empat kelas yaitu satu kelas untuk kelas eksperimen dan satu kelas untuk kelas kontrol. Pada kelas eksperimen diberi perlakuan menggunakan pembelajaran dengan Think-Talk-Write sedangkan kelas kontrol diberi perlakuan pembelajaran secara konvensional.

\section{HASIL DAN PEMBAHASAN}

Sebelum melakukan penelitian, maka dilakukan dulu uji prasyarat terhadap dua kelas yang akan digunakan dalam penelitian. Uji prasyarat tersebut meliputi uji kemampuan awal mahasiswa menggunakan uji t, uji normalitas populasi menggunakan SPPS 16.0 dan uji homogenitas variansi populasi menggunakan uji Bartlet.

Data statistik nilai Pre-Test dari masing-masing kelas disajikan dalam tabel berikut:

Tabel 2. Data Statistik Nilai Pre-Test Kelas Eksperimen dan Kelas Kontrol

\begin{tabular}{|l|c|c|}
\hline \multicolumn{1}{|c|}{ Statistik } & $\begin{array}{c}\text { Kelas } \\
\text { Kontrol }\end{array}$ & $\begin{array}{c}\text { Kelas } \\
\text { Eksperimen }\end{array}$ \\
\hline $\begin{array}{l}\text { Nilai Rata- } \\
\text { rata }\end{array}$ & 50,57 & 56,85 \\
\hline $\begin{array}{l}\text { Nilai } \\
\text { Tertinggi }\end{array}$ & 92 & 96 \\
\hline $\begin{array}{l}\text { Nilai } \\
\text { Terendah }\end{array}$ & 18 & 5 \\
\hline
\end{tabular}


Gambar 1. Nilai Pre-Test Kelas Eksperimen dan Kelas Kontrol

Untuk mengetahui kemampuan awal dari masing-masing kelas, maka statistik uji yang digunakan adalah uji t. Hasil perhitungan ini dengan taraf nyata $5 \%$ dan $\mathrm{dk}=90$ maka harga $\mathrm{t}$ pada tabel adalah 1,67. Dari proses perhitungan, ternyata hasil $\mathrm{t}=0,072<1,67$ sehingga $\mathrm{H}_{0}$ diterima. Jadi, dapat disimpulkan bahwa kedua kelas memiliki kemampuan awal yang sama.

\section{Uji Hipotesis}

Setelah uji asumsi terpenuhi maka dilakukan pengujian hipotesis. Hipotesis-hipotesis dalam penelitian ini diuji dengan menggunakan uji proporsi dan uji t. Daftar rincian nilai post-test dari kelas eksperimen dan kelas kontrol dapat dilihat pada tabel berikut :

Data statistik nilai post-test dari masing-masing kelas disajikan dalam bentuk tabel berikut :
Tabel 3. Data Statistik Nilai Post-test Kelas Kontrol dan Kelas Eksperimen

\begin{tabular}{|l|c|c|}
\hline Statistik & $\begin{array}{c}\text { Kelas } \\
\text { Kontrol }\end{array}$ & $\begin{array}{c}\text { Kelas } \\
\text { Eksperimen }\end{array}$ \\
\hline $\begin{array}{l}\text { Nilai Rata- } \\
\text { rata }\end{array}$ & $\begin{array}{c}62, \\
93478\end{array}$ & 72,41304 \\
\hline $\begin{array}{l}\text { Nilai } \\
\text { Tertinggi }\end{array}$ & 100 & 100 \\
\hline $\begin{array}{l}\text { Nilai } \\
\text { Terendah }\end{array}$ & 8 & 12 \\
\hline
\end{tabular}

Gambar 2. Nilai Post-Test Kelas Eksperimen dan Kelas Kontrol

Pembelajaran Matematika dengan Metode Think-Talk-Write efektif jika digunakan pada proses pembelajaran matematika untuk meningkatkan kemampuan komunikasi matematis mahasiswa pada mata kuliah Teori Bilangan. Dalam hal ini hasil posttest dari kelas eksperimen dihitung secara statistik dengan menggunakan uji proporsi satu populasi. Secara umum hasil perhitungan dijabarkan sebagai berikut: 
Keputusan Uji: $\mathrm{H}_{0}$ ditolak jika $z \geq z_{(0,5-\alpha)}$

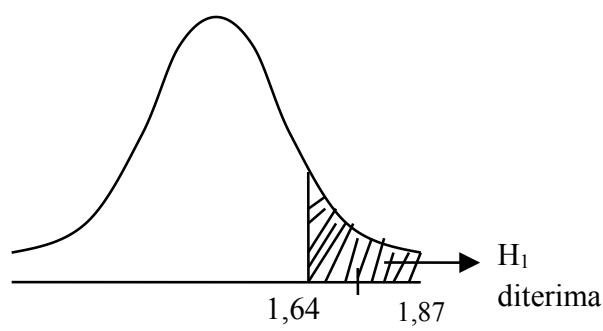

Gambar 3. Uji Hipotesis

Dengan taraf nyata $5 \%$ maka harga $\mathrm{z}$ pada tabel adalah 1,64. Dari proses perhitungan, ternyata hasil $\mathrm{z}=1$, $87>1,64$ sehingga $\mathrm{H}_{1}$ diterima (uji signifikasi). Jadi, dapat disimpulkan bahwa pembelajaran dengan menggunakan model Pembelajaran Think-Talk-Write efektif meningkatkan kemampuan komunikasi matematis mahasiswa ditinjau dari pencapaian KKM lebih dari $75 \%$.

Proses pembelajaran yang menggunakan model pembelajaran Think-Talk-Write lebih efektif dibandingkan dengan proses pembelajaran secara Konvensional untuk meningkatkan kemampuan komunikasi matematis mahasiswa. Dalam hal ini hasil nilai posttest dari kelas kontrol dan kelas eksperimen dihitung menggunakan uji t.
Keputusan Uji: $\mathrm{H}_{0}$ ditolak jika $t>t_{1-\alpha}$

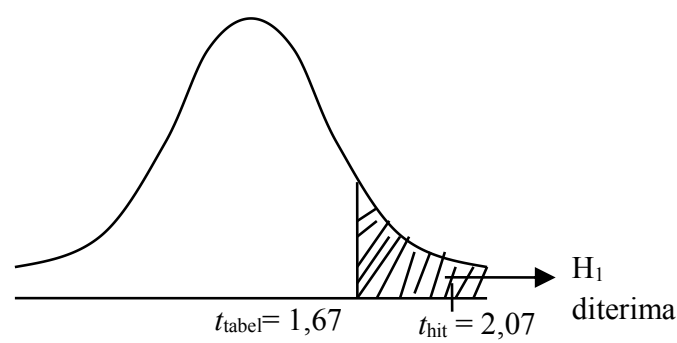

Gambar 4. Uji t post-test

Dengan taraf nyata 5\% maka harga $t$ pada tabel adalah 1,67. Dari proses perhitungan, ternyata hasil $t_{h i t}=$ 2,07> 1,67 sehingga $H_{1}$ diterima (uji signifikasi). Jadi, dapat disimpulkan bahwa pembelajaran dengan model pembelajaran Think-Talk-Write lebih efektif daripada pembelajaran konvensional untuk meningkatkan kemampuan komunikasi matematis mahasiswa.

\section{Analisis Keterlaksanaan Model Pembelajaran Think-Talk-Write}

Kegiatan observasi dilakukan untuk mengamati proses pembelajaran dengan model Think-Talk-Write . Dalam pengamatan ini proses pembelajaran diamati oleh beberapa pengamat. Pengamatan dilakukan oleh peneliti menggunakan lembar observasi yang berisi tentang catatan yang menerangkan proses pembelajaran dengan model Think-Talk-Write. Data statistik hasil observasi keterlaksanaan pembelajaran dengan model 
pembelajaran Think-Talk-Write adalah sebagai berikut:

Tabel 4. Hasil Persentase Observasi Keterlaksanaan Pembelajaran dengan Model Pembelajaran Think-Talk-Write

\begin{tabular}{|c|c|c|c|}
\hline \multirow{2}{*}{$\begin{array}{c}\text { Rata-rata } \\
\text { Presentase }\end{array}$} & \begin{tabular}{c} 
Pertemuan \\
\cline { 2 - 4 }
\end{tabular} & $\begin{array}{c}\text { Pertemuan } \\
2\end{array}$ & $\begin{array}{c}\text { Pertemuan } \\
3\end{array}$ \\
\hline Kriteria & $79,44 \%$ & $90 \%$ & $92,78 \%$ \\
\hline
\end{tabular}

Sehingga dapat disimpulkan bahwa selama proses pembelajaran menggunakan model pembelajaran Think-Talk-Write tingkat ketercapaian pembelajaran tergolong sangat tinggi.

\section{KESIMPULAN}

Berdasarkan hasil penelitian yang telah dilakukan oleh peneliti maka dapat diambil kesimpulan :

1. Model Pembelajaran Think-TalkWrite efektif digunakan dalam pembelajaran matematika untuk meningkatkan kemampuan komunikasi matematis mahasiswa sehingga mahasiswa yang mencapai nilai diatas 75 (kriteria tinggi dan sangat tinggi) lebih dari $75 \%$.

2. Proses pembelajaran dengan model Think-Talk-Write menuntut mahasiswa untuk berfikir dan menyampaikan ide-idenya secara lisan dan tulisan.

3. Model Pembelajaran Think-TalkWrite lebih efektif daripada pembelajaran konvensional pada pembelajaran matematika untuk meningkatkan komunikasi matematis mahasiswa. Hal ini dapat dilihat dari hasil perhitungan secara statistik dimana pada uji t harga $t_{h i t}$ komunikasi matematis lebih dari harga t pada tabel yaitu 2, $07>1,67$ (uji signifikan).

\section{DAFTAR PUSTAKA}

Deni Kurniawan. 2011. PembelajaranTerpadu. Bandung: CV. Pustaka Cendekia Utama

National Council of Teachers of Mathematics. (2000). NCTM Program Standards.Programs for Initial Preparation of Mathematics Teachers.Standards for Secondary Mathematics Teachers.http://www.nctm.org/ uploadedFiles/Math_Standards.

Sugiyono. 2009. Metode Penelitian Kuantitatif Kualitatif dan $R \& D$. Bandung: Alfabeta. 